Journal of Learning and Development Studies (JLDS)

DOI: $10.32996 /$ jlds

Journal Homepage: www.al-kindipublisher.com/index.php/jlds

\title{
Online-Based Learning: Challenges and Strategies of Freshman Language Learners
}

\author{
Barrera, Danica Jane U \\ College of Teacher Education, Western Mindanao State University \\ Corresponding Author: Barrera, Danica Jane U, E-mail: danicajanebarrera@gmail.com
}

\author{
ARTICLE INFO \\ Received: September 08, 2021 \\ Accepted: October 07, 2021 \\ Volume: 1 \\ Issue: 1 \\ DOI: 10.32996/jlds.2021.1.1.6
}

\section{KEYWORDS}

Online-based learning, virtual classroom, freshman language learners, challenges, strategies

\section{ABSTRACT}

The increasing demand for the implementation of an alternative learning scheme to aid the sudden setback in the field of education has been one of the most debated topics among the government and educational sectors worldwide. With the impossibility of face-to-face learning, the government had to devise an attainable learning substitution plan which resulted in the birth of online education. This study is one of the few studies that seek to determine the challenges and strategies used by freshman language learners in online education in the midst of a pandemic. Furthermore, a descriptive-qualitative design was employed in the study. Hence, the data were gathered using semi-structured interviews. The respondents for this study were identified by means of a purposive sampling technique. On that account, the respondents were handpicked in consideration to the inclusion criteria. Moreover, in depth individual interviews were conducted to seven respondents, five females and 2 males. To analyze the data, thematic analysis was utilized. The challenges that emerged in the study are the following: High-cost internet access, less social engagement and inactive class discussion, unfamiliarity of the new learning modality, internet connectivity, stress inducing school-works, lack of technological resources, locationrelated stressors and unpredictability of power outages. The paper concludes with the four emerging themes concerning the strategies freshman language learners use in online education and how those strategies aid the aforementioned challenges.

Published by Al-Kindi Center for Research and Development, London, United Kingdom.

Copyright (c) the author(s). This open access article is distributed under a Creative Commons Attribution (CC-BY) 4.0 license (https://creativecommons.org/licenses/by-nc-nd/4.0/)

\section{Introduction}

Throughout history, there have been various diseases that were acknowledged as the most widespread viruses across the globe-from the 1720 Plague to the 1820 cholera to the 1920 Spanish flu and now the Chinese Coronavirus which started its first attempt to unapologetically end lives in the advent of 2020. COVID-19 resulted in the disruption of the normalcy that we have been accustomed to for centuries (Saraswati, 2020). Unfortunately, education has been one aspect that could not escape the drastic changes made (Baber, 2020). As a result, schools and colleges across the world have been forced to close.

With the goal of maintaining full visibility of teaching modalities in the face of a pandemic, there is a growing demand for the educational system to stray away from the traditional face-to-face environment into a digital mode of language instruction (Dong, et al 2020); having said that, students must abandon the traditional mode of learning and instead shift their primary focus on adjusting to the quality education provided to them via their devices at home. Additionally, the conventional face-to-face classroom is losing its autonomy as an avenue for educational and pedagogical learning (Nguyen, 2015) because the ubiquity of the internet to hold interactive classes offers new opportunities.

Bezhovski and Poorani (2016) advanced that digital learning is a concept that has been around for more than a decade. It began to emerge around the time when social media and the internet were gaining popularity in the late modern period. Indeed, technological innovations have completely altered how people live today, particularly in educational contexts (Jan, 2017). Evidently, as the platform shifts from the bricks-and-mortar classroom to the virtual set-up, online-based education is put to test. In a similar direction, Singh and Thurman (2019) explained that web-based learning is defined as an educational environment that requires the use of digital equipment and involves students interacting with teachers and other students in a virtual class that is either synchronous or asynchronous. Since the virus' rapid spread wreaked havoc on the educational system, forcing educational 
institutions to close (Saraswati, 2020) there is a good chance that current technologies will be used more often for online courses especially now that the Commission on Higher Education (CHED) adapts flexible learning as the 'new norm.' As distance and online education rely much on information technology, such as the internet and $\mathrm{Wi}-\mathrm{Fi}$, gaps in their availability and education quality are increasing. Further, since the Philippines is one of the countries that have poor internet connection (Tria, 2020) students may have difficulties in taking classes online as utilizing current technology to perform things online necessitates using the internet. With the lack of strong internet connectivity, students may find it hard to perform well in their online education duties.

Online education grows increasingly popular, and many schools and institutions are working on ways to best distribute coursework to students. Stallings (2002) argued that as technology advances and more students choose to learn online, reinforcing innovative assessment techniques for the virtual learning platform is momentous. Additionally, in the study of Pollack and Wilson (2002) it was suggested that exploring existing problems and difficulties with higher education online learning is critical to provide a better framework for approaches to improve the student experience. On that account, Chen (2010) shed some light on how online technology such as email, virtual meetings, discussion panels and enterprise social networking can provide logical and coherent means to achieve educational aims intended for students who take online courses. It was also noted that these students typically have numerous background conditions Richardson (1999) that affect both their yearning for an online development setup and their academic environment achievement.

Following a review of the previously mentioned literature, a research gap emerges as although there is a growing need to identify the challenges confronted by students in online-based learning and determine the strategies they put into practice to learn effectively, very little has been explored concerning the additional encounters that students tend to face with the implementation of the strict pandemic protocols. In support of this, while the studies of Stallings (2002), Pollack and Wilson (2002), Chen (2010), and Richardson (1999) scrutinized how imperative evaluation techniques, and exploring online challenges and student backgrounds are as the need for online education arises, there is a dearth of literature on the challenges and strategies used by students concerning online learning with the unexpected adoption of an online learning policy as a result of a global epidemic. Additionally, while other studies tend to solicit data from teachers and students attending online classes, this paper specifically focuses on the viewpoints of freshman language learners about the newly implemented online learning alternatives. Inarguably, the previously discussed literature were not able to incorporate freshman language learners' perceptions on the challenges and strategies they utilize to endure the new learning modality. Finally, examining the potential issues and learning strategies of students in online-based learning during a pandemic is crucial and critical for providing valuable information in support to the development of quality online education. As a result, the current study aims to fill in the gaps by gathering valuable evidences explicitly from freshman language learners and looking into the challenges they face and the strategies that they find useful when learning online.

\section{Review of Related Literature \\ 2.1 Online-Based Learning}

The omnipresence of technology and other online platforms in the delivery of classroom instruction has sparked controversy in the field of research. This is because, in time-sensitive problems, technological progress frequently surpasses the rate of scientific inquiry (Tess, 2013). In the last decade, the rise to popularity of social media has had a growing impact on higher education Evans (2014), and many recent studies show how important it is to incorporate social media into the classroom. Online-based learning as explained by Smith (2016) arose as a result of the advancement of technology and some educational institutions realized the potential of technology as a medium for classroom instruction. However, with the whole world in panic and in disorganization because of the global pandemic, it can be stated that online-based learning can have both benefits and drawbacks in the educational process.

The relevance of integrating online learning to mobile platforms is growing Han (2016), with studies indicating that learners who are younger and work a full-time job utilize versions of educational management systems. Relative to this claim is the study of Chen C. K. et al. (2012), where they emphasized that the majority of studies show that using blended technologies for online courses has a good impact. Efficacy in terms of cost, enhanced connectivity, adaptability, and customizable and collaborative work opportunities are only a handful of the benefits. Moreover, Allen and Seaman (2013) affirmed that online education has the prospective to reach a wider audience, thereby bringing learners who are traditionally neglected in terms of educational opportunities on an equal footing. Further, Andreatos (2012) contended that students can offer reasoned responses in asynchronous online communities where there are less societal stressors that come with direct conversation. Online courses and activities have been reported to improve the quality of education, increase commitment, as well as motivate learners. Additionally, Garrison (2011) has discussed the potential utility of online communities as learning hubs and their ability to establish learning centers that interest both groups and individuals. He emphasized that when students speak their opinions, they do not have to feel as if they are interrupting others. Furthermore, the amount of time available in online forums for reasoned responses has the potential to stimulate in-depth conversations. 
However, despite the numerous studies that support the assertions that online communities can facilitate effective learning, Murphy (2014) points out a contradiction in research on the effectiveness of online learning. An absence of relational connectedness or a great deal of distance can be barriers in online education, resulting in disinterest and low retention rates. Corroborating to this statement is the claim of Forbes (2013) stating that in virtual environments, there are fewer social cues, which makes communication more difficult. This claim is supported by Gedera et al. (2015) where they posited that there are times when students and professors misinterpret each other's motives as well as each other's opinions and generate misleading impressions of one other. In a similar vein, Ahmad, Ghani, and Malik (2020) noted that the success of an online learning style may also be hampered by a lack of connections, electronic gadgets, and poor internet. Evidently, online setups need internet connections to communicate with others and for online programs to work properly. As a result, success in online schools may be difficult to attain when the internet is weak.

The prominence of online-based learning is still increasing, and it has brought certain rewards and pitfalls to the academic trend. However, it is critical to investigate the challenges as well as the strategies of the students that prove to be useful in online education to identify the strengths and to aid the weaknesses. Hence the current study.

\subsection{Freshman Language Learners' Challenges in Online-Based Learning}

Despite the various promises about the benefits and potential usefulness of online learning, certain research continuously show low completion rates of courses and significant rates of dropout that are seen as hindrances in online education. Inarguably, the bigger the numbers of dropouts, the longer schools are closed Buckler et al. (2020). As a result of the pandemic, many parents are unemployed, and their economic plight has deteriorated. On that account, some parents may find themselves unable to pay for their children's education. Children may be compelled to work in order to help support their families financially. As online learning necessitates the use of technology devices for virtual classrooms, low-income students may be unable to afford those (Lai \& Kristonis, 2006). As a result, underprivileged learners may be denied access to online education. According to Sharma (2020), roughly $8 \%$ of households and $12 \%$ of universities have internet and digital device accessibility. This implies that for many parents and schools, it is ridiculously expensive to have access on technological resources and the web.

Moreover, according to Islam et al. (2015), technology, styles of learning, ethnicity, technical training, poor time management skills and instructional e-learning obstacles are some of the challenges that commonly occur in an online environment. In light of this, the study of Alpala and Florez (2011) stated that since it takes time for learners to become familiar with emerging technologies, virtual learning should be implemented gradually. This means that virtual learning should not be implemented without proper training and planning so that students do not have a hard time learning in a virtual environment.

Further, a study conducted by Saraswati (2020) examined that the coronavirus outbreak has a significant effect on young people's physical and mental status. On that note, complications concerning psychological distress are likely on the rise. This is because social media and digital devices are becoming increasingly addictive to some children (Georgiou, 2002). All of these hindrances aforementioned could have an indirect impact on the students' ability to learn. Henceforth, freshman language learners' online learning experience, specifically the challenges that they face, are highlighted in the study.

\subsection{Freshman Language Learners' Strategies in Online-Based Learning}

Learning strategies have been viewed as tools that language learners might employ to help them adjust to online education faster or more effectively. Wenden and Rubin (2011) further exemplified that learning strategies are any set of activities, procedures, plans, or the learners' techniques for making the learning, retention, recall, and the application of knowledge easier. Corroborating to this is the study of Richards, Platt, and Platt (1992) which concluded that learners' use of learning strategies could be an intentional behavior and a mental process to help them better absorb, learn, or store new knowledge.

There are two types of learning strategy as introduced by (Oxford, 1990); the direct and indirect strategy. Considering this, Brown and Lee (2015) advanced that Oxford's classification of learning strategies is often acknowledged as the most extensive. It was found out that retention tactics, reasoning approaches, as well as compensating techniques prove to be examples of direct learning strategies, whereas, emotional strategies, societal strategies, and self-cognizant strategies, are examples of subsidiary learning techniques. Furthermore, in the study of Bae and Kim (2018), it was found out that learners are more likely to employ cognitive techniques such as conceptualization or deductive reasoning regarding online content while using various digital devices and wired/wireless internet connection, especially in their online learning. It has also been discovered that during web browsing, learners employ many metacognitive strategies such as planning, organizing, and self-monitoring, as well as reading strategies such as skimming, scanning, understanding topics, and inferring.

Since the 1990s, research concerning learners has been actively pursued in the domain of English language teaching Li (2005) and techniques for evaluating different types of learning methods have become increasingly fragmented and systematized. According 
to previous research, language learning contexts, as well as individual learner factors such as English ability, previous learning experiences, motivation, attitude, and beliefs about education, have a substantial influence with the utilization of educational schemes. However, Prensky (2001) noted that the qualities of today's learners differ from those of earlier generations. This means that since the modality in education from the early years was entirely different from the modality of today, learners' learning strategies also underwent various drastic changes. The pandemic has had a debilitating effect on the educational system, and it has resulted in a tremendous deal of uncertainty. Therefore, it is vital to distinguish students' learning strategies since students today receive information in a variety of ways and execute a range of tasks in a variety of approaches (Teo, 2013).

\subsection{Research Questions}

1. What are the freshman language learners' challenges in online-based learning?

2. What are the freshman language learners' learning strategies in online-based learning?

\section{Method}

\subsection{Research Design}

The current study aims to determine the challenges and strategies of freshman language learners in online-based learning. It made use of a qualitative research design. For a variety of reasons, qualitative analysis is a necessary tool Baden (2010, as cited in Blackmon \& Major, 2012). It provides an understanding of a situation by relaying stories Yang and Cornelius (2004) rather than determining causes and effects. Furthermore, semi-structured interviews were conducted. In view of this, a semi-structured interview's major advantage is that it allows for new ideas and questions to emerge during the conversation (Harding, 2018). This research does not seek to make broad generalizations; rather, it is concerned with accurately portraying the ongoing phenomenon under investigation.

\subsection{Participants}

The participants in this study are seven freshman language learners from the college of teacher education of Western Mindanao State University, who are pursuing a bachelor's degree in English and are studying online. Moreover, respondents' enrolment in an educational platform with a field of specialty in English is required otherwise; he or she would be unqualified to participate in the study. The respondents for this study were chosen using a purposive sampling technique. On that note, the researcher chooses who can provide information based on their knowledge and experience (Bernard, 2002 as cited in Ramos et al., 2020). Inarguably, the participants' perspectives are crucial to be heard Booth (1997) as various people experience online learning in different ways.

\subsection{Instruments and Data Collection}

In securing the necessary information, a semi-structured interview which was prepared by the researcher and was matched with the research questions was used. Semi-structured interviews, according to Jamshed (2014), are in-depth interview method in which respondents must answer open-ended questions. Harding (2018) affirmed as he further noted the benefit that semi-structured interviews are capable of providing. Accordingly, it allows for the emergence of fresh ideas and questions during the discussion. Furthermore, the instrument was verified by Professor Ericson Olario Alieto, a Doctor of Philosophy in English Language Teaching and pilot tested to two first-year language learners. After the pilot testing, interviews were conducted with the seven final respondents. Since direct interviews were prohibited in accordance to the government's health protocol, the interviews were performed over the phone. In relation to that, voice recordings of the conferences were made and were written down for the analysis of data. Nevertheless, the pieces of information were organized into themes depending on the study questions. Then, the researcher examined the emergent themes as expressed by the seven final participants, which resulted in the final data analysis results.

\subsection{Method of Analysis}

To evaluate the data from the study, thematic analysis was employed. Thematic analysis, as advanced by Braun and Clarke (2006) is ought to be a cornerstone technique for qualitative research since it teaches key abilities that can be used in many other types of qualitative research. In support of this, Bernard and Ryan (2000) maintained that in many qualitative methods, thematic analysis is a technique that is employed. It is not a stand-alone approach; rather, it is something that may be utilized to aid researchers in their study. The purpose of this strategy in the analysis, according to Maguire and Delahunt (2017), is to uncover themes and categories that are relevant to discuss the research problems regarding the data collected. Since thematic analysis is a qualitative research technique which can be used to a variety of interpretations and problem statements Moules, Norris, Nowell and White (2017) this is a useful strategy for assessing diverse respondents' points of view and generating conclusions (Braun \& Clarke, 2006). As a result, the research used this approach of analysis as it was regarded suitable for the current study.

\section{Results and Discussion}

The results of the data analysis are presented in this section, answering the two research questions concerning freshman language learners' challenges and strategies in online-based learning. 
Table 1 : What are the Freshman Language Learners' Challenges in Online-based Learning?

\begin{tabular}{|c|c|c|}
\hline Themes & Percentage & Excerpts \\
\hline High-cost internet access & $\begin{array}{l}2 \text { out of } 7 \text { or } \\
28.58 \% \text { of the } \\
\text { respondents }\end{array}$ & $\begin{array}{l}\text { 'Data is really good, however, it is really costly. You're going to } \\
\text { spend hundreds of load for a week and then imagine the cost of it } \\
\text { having it this school year. I had to make an extra effort...' } \\
\text { (Participant 1) } \\
\text { 'I belong from a poor household and it's hard because sometimes } \\
\text { we do not have money for the load for my cellular data ...' } \\
\text { (Participant 3) }\end{array}$ \\
\hline $\begin{array}{l}\text { Less social engagement } \\
\text { and inactive class } \\
\text { discussion }\end{array}$ & $\begin{array}{l}3 \text { out of } 7 \text { or } \\
42.86 \% \text { of the } \\
\text { respondents }\end{array}$ & $\begin{array}{l}\text { 'I find it hard to understand the lesson all by myself. Sometimes, I } \\
\text { hope that it is face-to-face so that when a teacher is talking in front } \\
\text { of us, explaining the lesson, we understand it well. (Participant 1) } \\
\text { 'My experience was challenging because there is no actual teacher } \\
\text { who is really teaching in front. I have a hard time grasping the } \\
\text { lectures and participating in class discussions when there is no } \\
\text { teacher in front of me...' (Participant 2) } \\
\text { '...and, we could not interact with people personally. I want to talk } \\
\text { with my classmates personally because I want to really know them } \\
\text { more, but I cannot. It is draining mentally and physically } \\
\text { frustrating...' (Participant 6) }\end{array}$ \\
\hline
\end{tabular}

\begin{abstract}
Unfamiliarity of the new 3 out of 7 or 'I have said that this is way different from face-to-face classes. The modality $42.86 \%$ of the learning is really new to me because you're going to adjust your respondents perspective...' (Participant 1)

'I have no idea how online-class works considering that this is my first year in college...' (Participant 4)

'I feel unmotivated with the new modality I'm not used to it. But then I have to go with the flow...' (Participant 7)
\end{abstract}

$\begin{array}{lll}\text { Unstable } & \text { internet } & 4 \text { out of } 7 \text { or } \\ \text { connectivity } & 57.14 \% \text { of the } \\ & \text { respondents }\end{array}$

'Internet connection is a problem. There was one time we had an exam, and the teacher gave as a specific time to submit the exam. But then I submitted it late I blame it to the internet...' (Participant 2)

'I cannot always guarantee that the signal is okay especially when it rains. During one of our subjects, it was a live quiz and the signal here in Basilan was cut off because of the weather. I tried to ask the teacher if I can be given a special quiz or a consideration but then she declined. I wasn't able to take the exam...' (Participant 5)

'The internet connection is not stable There was an exam for a major subject, and we were asked to open our cameras, but the internet is not cooperating, so I got a really low score...' (Participant 6)

I was not able to join the classes for the first few weeks. The internet connection in our house is very poor...' (Participant 7) 


\begin{abstract}
Stress-inducing school- 3 out of 7 or In the online class, it is not like that because some school-works are works $\quad 42.86 \%$ of the just given and then we are just going to understand it on our own...' respondents (Participant 1)

'Sometimes I feel pressured and stressed especially if I have so much school-works. I have a hard time keeping up with the lectures and feeling motivated because I feel like I'm the only one who has a hard time, and my classmates don't...' (Participant 4)

'There are professors that would give requirements one after the other. I find it stressful to edit and review my works...' (Participant 6)
\end{abstract}

\begin{tabular}{ll}
\hline Lack of technological & 2 out of 7 or 'I do not have enough learning resources such as the laptop which \\
learning resources & $\begin{array}{l}28.58 \% \text { of the } \\
\text { respondents }\end{array}$ \\
& $\begin{array}{l}\text { makes online-based learning hard. It is a misconception to assume } \\
\text { make online learning effective. Still, it is what it is happening today } \\
\text {...' (Participant 2) }\end{array}$
\end{tabular}

'Although I do not have the laptop, I have my phone. However, this causes disadvantages because there are features in the laptop which is not evident in the phone. I also feel left behind when I know that my classmates have their own laptop, and I don't.' (Participant 4)

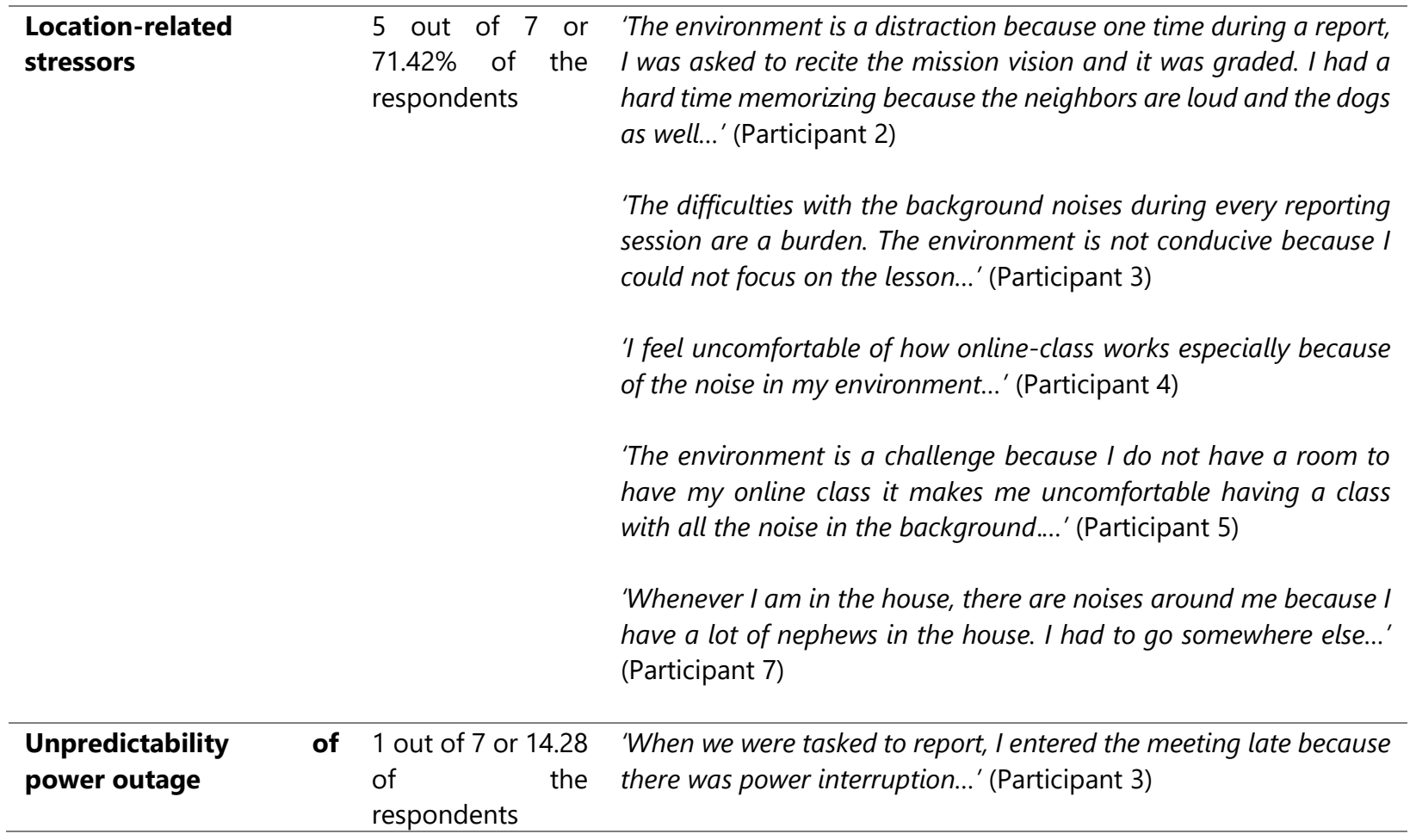

Table 1 highlights the respondents' challenges with online-based learning. According to the data, there are eight distinct themes. Primarily, high-cost internet access, in which two out of seven respondents stated that they have encountered challenges in learning online mainly because they were not provided with enough financial support system from their parents as they belong to 
a family of low social status. The excerpt, 'I belong from a poor household and it's hard because sometimes we do not have money for the load for my cellular data' demonstrates that a lack of funds is a hindrance to online learning.

Participant 3 mentioned that having no financial assistance to buy the necessary data load needed to attend online classes is a burden that every poor student needs to endure. Hence, he or she cannot perform well in online classes. Furthermore, participant 1 elaborated that attending classes is an everyday hurdle to those who are struggling not only academically but also financially. Unfortunately, in a time of crisis, they need to work for their education.

Parents from poor and rustic regions, as Tiruneh (2020) posited, are hesitant to support their children in online education as financially unstable parents would rather have their children continue to provide manpower and assistance in their livelihood for the survival of the family. Phuyal (2020) affirmed, stating that most people in poorer countries cannot afford to spend money on data to broaden their horizons as they must prioritize their food in order to survive in such a crisis. This is because many people are dying of starvation as a result of a massive worldwide economic meltdown (Alon et al., 2020). Further, this claim was supported by Manso and Owusu (2020) as they explained that COVID-19 has placed undue financial and social strain on low-income households. Henceforth, it is only logical for parents to reconsider between sending their children to school and having them toil at the workplace. In light of this, Albrecsten and Giannini (2020) suggested that schools may consider giving financial assistance such as scholarships to students who have been adversely impacted by the consequences of the pandemic or whose economic status has made it extremely difficult for them to attend school.

Freshman language learners also experience challenges in online-based learning due to the unfamiliarity of the new learning modality. Participants 1, 4, and 7 share the same concern. As participant 4 narrates 'I have no idea how online-class works considering that this is my first year in college' it can be inferred that being a first-year college student and having no knowledge on the new learning platform serves as a limitation in performing online tasks. This claim was supported by Halupa (2008) claiming that society has become increasingly reliant on technology and although it offers numerous advantages, it also has concerns, especially for young people. Evidently, Excessive use of technology can have a harmful impact on a child's physical, mental, emotional, and social health. The same issue is prevalent in the statements of participants 1 and 7 as they further explained that they must adjust their perspectives as the change in the educational environment has created huge differences that require their utmost understanding and adaptability.

Online learning has taken the place of the conventional learning normalcy in the classroom Atmojo (2020) and since then, there have been a number of consequences. The abrupt transition from traditonal education to innovative education has surprised both teachers and students because it was not anticipated. Mohalik and Sakoo (2020) further noted that the abrupt switch from a traditional approach to learning to a revolutionary approach to learning that incorporates technology left students and teachers with no time to organize course delivery, evaluations, technical preparations, or provide any assistance. Further, this claim was supported by Pandit (2020) claiming that in most schools, aside from the unavailability of technology, unfamiliarity among teachers and students is a barrier to distant learning. As a result, teachers and students must adjust to certain modifications in their classroom undertakings (Bhaumik \& priyadarshini, 2020) as teachers' techno-pedagogical strategies and the technological abilities of students needed to be improved.

Moreover, 3 out of 7 participants expressed that less social engagement and inactive class discussions are challenges in their online learning experience.

This viewpoint is supported by the following excerpts.

'I find it hard to understand the lesson all by myself. Sometimes, I hope that it is face-to-face so that when a teacher is talking in front of us, explaining the lesson, we really understand it well. (Participant 1)

'My experience was challenging because there is no actual teacher who is really teaching in front. I really have a hard time grasping the lectures and participating in class discussions when there is no teacher in front of me.' (Participant 2)

The participants discussed the difficulty in understanding lectures in online-based learning with the absence of the physical classroom and an instructor that is physically present. According to Dunlap and Lowenthal (2014), the formation of profound and meaningful learning experiences in distance learning is dependent on the presence of the teacher and social presence. Henceforth, it can be probed that to some freshman language learners, virtual classrooms that lack student and teacher engagement is deemed ineffective if the aim is to provide an alternative learning milieu. Numerous studies recommend high instructor involvement in asynchronous internet discussion Blignaut (2003), and multiple studies in the literature review have backed up the importance of teacher presence. This is because student engagement is positively correlated with the teacher's constant participation in an online 
class (Dennen, 2005). Relatively, it reveals that learners may question the intructors' dedication for the improvement of the class, seek constant responses and reassurance, and resent any apparent deficiency in cooperation that is apparent with the physically absent instructor (Lynch, 2004).

A similar idea is mentioned in another excerpt.

'...and we could not interact with people personally. I want to talk with my teachers and classmates face-to-face because I want to really know them more and I want to really express myself to them, but I can't. It is draining mentally and frustrating.' (Participant 6 )

It can be noticed that participant 6 finds online learning hard as they could not interact well with their teachers and peers. This claim is supported by Forbes and Gedera (2019) positing that students and teacher may face difficulty in conveying clear expectations of one another throughout online interactions, as they interact online. On that note, Gedera et al. (2015) further affirmed stating that interpersonal distance or a lack of relational connection are two additional barriers to online learning which can lead to disinterest and low retention rates. Further, since profound and significant cognitive-processing activities and evaluations stimulate students' engagement and presence, resulting to improved metacognitive awareness (Sands \& Sobel, 2007), the lack of communication between students in an online and virtual classroom may hamper the quality of the students' learning experiences (Anderson, et al., 2001).

Continuing, 4 out of 7 respondents shared how the unstable internet connectivity proved to be a challenge in their online education.

This idea is emphasized in the following excerpts.

Internet connection is a problem. There was one time we had an exam, and the teacher gave us a specific time to submit the exam. But then I submitted it late I blame it to the internet.' (Participant 2)

'The internet connection is not stable There was an exam for a major subject, and we were asked to open our cameras, but the internet is not cooperating, so I got a really low score.' (Participant 6)

With the growth of numerous digital devices and the popularity of online networks and Wi-Fi accessibility, digital media adoption has become a need rather than a choice (Bae \& Kim, 2018). However, participants 2 and 6 advanced that internet connectivity hinders their online learning experience and deters their academic performances. Corroborating to this, it was advanced by Brown (2017 as cited in Bayad \& Bayad, 2020) that the use of strong internet connection is vital when one aspires to start education in an online platform. Unfortunately, the Philippines, as explained by Akamai (2017, as cited in Tria 2020) is one of the countries with poor internet access therefore, it is logical to draw the conclusion that most learners suffer from instability of internet connection. In the study of Karal et al. (2011), they found out that the difficulty in internet connectivity is one of the most frequently occurring hindrance that most of the students face in online education. Considering this, Saraswati (2020) affirmed stating that since distance and online education rely on technology resources, such as the internet, disparities in their accessibility are forming breaches in the academic quality.

Stress-inducing school-works is also one of the challenges that freshman language learners face. 3 out of 7 respondents explained that the overlapping school-works are a burden that they carry every day for their online education.

The following excerpts support this claim.

'Sometimes I feel pressured and stressed especially if I have so many school-works. I have a hard time keeping up with the lectures and feeling motivated because I feel like I'm the only one who has a hard time.' (Participant 4)

'There are professors that would give requirements one after the other. Hence, I find it stressful to edit and review my works.' (Participant 6)

The COVID-19 pandemic is wreaking havoc on young people's health and well-being. Some students, for example, participants 4 and 6 may experience significant levels of stress because of the loss of learning opportunities caused by the shift in the learning platform. With the increase of online activities given to students Jan (2020), it can be posited that complying with school-works may become a burden for them to bare. From the excerpts, it can be deduced that stress rooted in the overlapping school-works is a challenge in online-based learning. On that account, Dominguez et al. (2001) acknowledged this claim as they posited that although using the internet and social media to assign group activities and online assignments could be a good way to incorporate

Page | 60 
collaborative learning activities into web-based courses, those taking many classes online, however, may be less engaged in managing the online classroom environment due to work stress. Corroborating to this is the study of Cohen (2003) which argued that as technology lacks a human component, students learning online may experience feelings of seclusion, hence the stress.

Furthermore, 4 of the respondents expressed that the lack of learning resources is the challenge that they face in the online learning platform.

This claim is reflected in this excerpt.

'Although I do not have the laptop, I have my phone. However, this causes disadvantages because there are features in the laptop which is not evident in the phone. I also feel left behind when I know that my classmates have their own laptop, and I don't.' (Participant 4)

Participant 4 shares that having a lack of learning materials or learning resources in online education is a risk that they must take as it slows down their academic progress. This may result in low self-esteem and poor academic performance.

The following excerpt supports this claim.

'I do not have enough learning resources such as the laptop which makes online-based learning hard. It is a misconception to assume that simply uploading notes or having the lecture videotaped will make online learning effective. Still, it is what it is happening today.' (Participant 2)

Apparently, there is an increasing need for students to be equipped with the latest technological resources for a better online learning experience. However, as Phuyal, (2020) argues, the accessibility to technological devices is a privilege, not every student can get. It is a fool's errand to be exposed to a battlefield without a gun to survive. The same goes with enrolling in online classes without the availability of the needed resources for effective learning. According to Mahyoob (2020) the absence of technological learning devices hampers the learning experience of students learning online. Considering this, participant 4 may have mentioned that having mobile phone alone while studying online is still a disadvantage as there are specific high-tech choices available in other technological devices that are not available in the mobile phone. With this contention, it can be inferred that the lack of high quality learning devices may result to the decrease of students' positive learning outcomes.

Continuing, since online-based education forces students to have their education in their homes, location-related stressors are evident.

This idea is supported by the following extract.

'The difficulties with the background noises during every reporting session are a burden. The environment is not conducive because I could not focus on the lesson.' (Participant 3)

'I feel uncomfortable with how online class works especially because of the noise in my environment.' (Participant 4)

Participants 3 and 4 claimed that participating in online classes makes them uncomfortable as there are background noises that might be heard in the virtual classroom and create distractions. This is a result of a less conducive learning space. As a result, this may affect their participation in class discussion and lessen their chances of having an avenue for a creative expression of inputs. This holds true with the claim of Tomei (2006) that students seem to be less comfortable in online learning situations. This claim was backed by the findings of Pukkaew (2013) which concludes that online students are concerned about the communication platforms given by the institution's course system which implies that students' views may be hampered by the formalities of online modalities. Difficulty in concentration, according to Belgica et al. (2020) is one of the challenges in distance learning. There are certain noises and distractions that are inevitable when one is having classes at home such as the noises from the neighborhood and the likes. These may create a lousy learning space for the students and as result they may encounter retention problems.

The last challenge to discuss is the unpredictability of power outages. The excerpt 'When we were tasked to report, I entered the meeting late because there was power interruption.' proves that the system blackouts are inevitable and are causing distractions and hindrances among freshman language learners in their online learning experience.

This finding is explained by Forbes (2020), advancing that unprecedented circumstances, such as power outages during online education, make equal access extremely difficult for disadvantaged students. This may be true as many students rely on school as 
a stable environment, making it difficult for them to adjust to online learning during adverse conditions. To further explain, Vox (2020) posited that this 'inequality' between privileged and underprivileged students in online education is classified as the 'digital divide.' When students are attenting their online classes, there is a need for a power source for their wifi cables and computers as well as their mobile phones. However, the unpredictability of power outages may prove to create a negative side effect on the flow of learning among students. This may hinder the students from passing their works on time and as well as concentrtaing on the topic presented to them on the screen.

Table 2 : What are the Freshman Language Learners' Learning Strategies in Online-based Learning?

\begin{tabular}{lll}
\hline Themes & Percentage & Excerpts \\
\hline \multicolumn{1}{c}{ Employing good } & 3 out of 7 or 'I communicate with my classmates and talk to them about my \\
communication and social & $42.86 \%$ of the experiences to know if they also experience the same thing for me \\
skills & respondents & to cope...' (Participant 1)
\end{tabular}

'Also, if I was having a hard time getting the main points of the subjects, I ask help if I cannot handle it from my classmates and friends...' (Participant 2)

'I also ask some of my classmates about the requirements to be done...' (Participant 7)

\begin{tabular}{ll}
\hline 'racticing Independent & 2 out of 7 or 'I also don't just rely on the teacher, I always self-study...' \\
Learning & $28.58 \%$ of the (Participant 3) \\
respondents
\end{tabular}

'I would read all of the learning materials given to us by the teachers. I would not neglect my studies even if is tiring...' (Participant 6)

\begin{tabular}{|c|c|c|}
\hline \multirow[t]{3}{*}{ Utilizing the web } & $\begin{array}{l}3 \text { out of } 7 \text { or } \\
42.86 \% \text { of the } \\
\text { respondents }\end{array}$ & $\begin{array}{l}\text { 'The utilization of the internet especially the YouTube app. I get } \\
\text { the lecture and then go to YouTube and search for it...' } \\
\text { (Participant 2) }\end{array}$ \\
\hline & & $\begin{array}{l}\text { 'I utilize the internet a lot especially the YouTube...' (Participant } \\
\text { 5) }\end{array}$ \\
\hline & & $\begin{array}{l}\text { 'I just always check the google classroom and the MS teams to } \\
\text { keep myself updated all the time...' (Participant } 7 \text { ) }\end{array}$ \\
\hline $\begin{array}{l}\text { Considering a conducive } \\
\text { learning space }\end{array}$ & $\begin{array}{l}3 \text { out of } 7 \text { or } \\
42.86 \% \text { of the } \\
\text { respondents }\end{array}$ & $\begin{array}{l}\text { 'I also look for places where the environment is less stressful and } \\
\text { where the signal is better. I always find ways to get out of the } \\
\text { house to find a place to study in peace...' (Participant 3) }\end{array}$ \\
\hline & & $\begin{array}{l}\text { 'Consider a study place and never do your online class in bed } \\
\text { because you might feel a sudden urge to take a nap...'(Participant } \\
\text { 4) }\end{array}$ \\
\hline
\end{tabular}

Table 2 summarizes the strategies used by respondents for online learning. Four distinct themes emerged from the data. Employing good communication and social skills is the first strategy and the excerpt 'I communicate with my classmates and talk to them about my experiences to know if they also experience the same thing for me to cope...' prove to be a shred of evidence that talking to peers and being more socially aware helps in surviving the new learning modality. This finding is elaborated by Schrander (2015) stating that there are many different types of people with whom students can build rapport with due to online communication. Indeed, there are various sorts of individuals that a learner may be able to communicate within an online environment and this can serve as a benefit for them to find an avenue for self-expression. 
This is supported by the following excerpt.

'Also, if I was having a hard time getting the main points of the subjects, I ask help if I cannot handle it from my classmates and friends since they are just one chat away.' (Participant 2)

This notion is supported by the findings of Smith (2016) which explained that students can begin the process of interacting on an equal ground through online communication without being hampered by obstacles that may hinder them in face-to-face interaction. This is especially true since asking for help on an online platform seems to be much easier than asking for help in person. Studying through an online platform offers many advantages. One of those is the pleasure of being able to communicate with a wide array of people through the internet. Besides, with the new generation of students who are capable of maneuvering through the rapid evolution and advancement of technologies, they may favor conversations held through the net rather than the usual face-to-face interaction.

Continuing, 2 out of 7 respondents narrated that practicing independent learning or self-study is one of their strategies to perform well in online education. In the excerpts 'I would read all of the learning materials given to us by the teachers. I would not neglect my studies even if is tiring...' and 'I also don't just rely on the teacher, I always self-study.' it can be inferred that freshman language learners do not solely depend on the learning materials given to them by their teachers and they always find time to self-educated at all costs. This is one strategy that could help them retain and recall lessons better and easier. This claim is found to be significantly true in the study of Serwatka (2003, as cited in Yun, 2013) as they explained that online education entails a substantial amount of self-discipline and determination. This holds true when online units are completed independently and self-study modules rather than students interacting is a part of an online community (Smart, 2006). Since learners are now obliged to comprehend the lessons at their own speed at home, allotting enough time to concentrate on the lessons presented to them is how they would cope.

The use of the internet or utilizing the web is also one of the strategies introduced by the respondents.

The following excerpts confirm the claim.

'The utilization of the internet especially the YouTube app; I get the lecture and then go to YouTube and search for it.' (Participant 2)

'I just always check the google classroom and the MS teams to keep myself updated all the time.' (Participant 7)

Participants 2 and 7 shares that the strategy they use to endure online education is to take advantage of the internet. This idea is supported by the claim of Allias et al. (2012) as they posited that students have already been trained in digital learning strategies using social networking sites and the Internet, with positive outcomes in the digital learning environment. Within the comfort of their own homes, three out of seven respondents have claimed that the use of internet has been helping them with their performances in online education. Inarguably, the world wide web has been posing countless benefits in the online community. Additionally, Dillenbourg and Schneider (2002) noted, the internet may also be used to break down barriers within our society and facilitate the transition between schools and universities. In light of this claim, it can be advanced that web-based learning platforms and applications such as the chrome, YouTube, MS teams, and Google meet are substantial tools for a better online learning experience not only to facilitate learning but also to create connections between learners and instructors.

The final strategy that was discussed by the participants is considering a conducive learning space. With the excerpts 'I also look for places where the environment is less stressful and where the signal is better. I always find ways to get out of the house to find a place to study in peace.' and 'Consider a study place and never do your online class in bed because you might feel a sudden urge to take a nap.' it is reasonable to infer that finding an adequate learning space is a key factor to enhance one's online learning experience.

Evidently, two out of seven participants mentioned that they would move from one place to another in search for a better signal outside their homes. In such a way, they can be able to participate more in class discussions without having to worry about the conduciveness of their learning space. To support this claim, Schlechty (2002) elaborated that the information being taught is more likely to be understood if an environment is established in which students are determined to be genuinely involved. Further, Ortiz (2017) explained that students are more likely to participate in the task if they are in a comfortable environment that allows for better absorption of knowledge. These claims support the assertions of participants three and four that with a conducive learning space, they are more likely to retain what the teachers present to them without having to stress-out about certain factors that affect their learning performances. 


\section{Conclusion}

The purpose of this research was to discover the challenges and strategies freshman language learners usually encounter when learning online. Subsequently, the results of the study clearly show that the respondents have a wide range of opinions about online learning. Nevertheless, the following findings are drawn from the data supplied in the study.

High-cost internet access, less social engagement and inactive class discussion, the unfamiliarity of the new modality, unstable internet connectivity, stress-inducing school-works, lack of technological learning resources, location-related stressors, and unpredictability of power outages are among the challenges that freshman language learners face in their online learning. However, with strategies like employing good communication and social skills, switching sim cards for mobile data use, independent learning, utilizing the web, and considering a conducive learning space, these issues are given proper attention and adequate solutions.

Further, this research scrutinized that the most common issue in online-based learning is the location-related stressors with 5 out of 7 respondents claiming that the environment is not conducive for a quality online education followed by the unstable internet connectivity with 4 respondents sharing similar concerns. Conversely, the most common strategy employed by freshman language learners in online-based learning is to use good communication and social skills, as well as to use the internet, with 3 out of 7 respondents advancing the same viewpoint.

Future studies around the same ground is recommended to interpret as well as provide generalizations about the verdicts manifested from this study. Involving a significant total of participants from other urban and rural areas, all with diverse backgrounds is encouraged.

\section{Implications}

The following are the educational implications unveiled from the results of this study:

First, with the varying challenges that freshman language learners encounter in online-based learning, it can be inferred that student face difficulties in the new norm as there are many contributing factors that negatively affect their learning. Unfortunately, not all students are financially privileged to sail through the online modality without having to face turbulences. Henceforth, it is important for teachers, school administrators, and the government as a whole to address these issues and provide assistance to those who are in need of it.

Second, as freshman language learners' learning strategies were also unlocked in this study, it can be posited that the vitality of knowing the students' side of the story on how they manage to survive in the new norm is highly needed for teachers so that they can be able to guide their students into performing better in classroom discussions and the likes. Teachers need to exert more effort in their online classroom not only through developing learning materials for students but also to be more considerate of their situations and become the backbone of their students for them to appreciate the innovative shift in the learning platform. By so doing, quality online education is reachable.

\section{References}

[1] Ahmad, M., Ghani, M., \& Malik, A.M. (2020). Exploring the relation between English and online mode of learning during covid-19. Linguistic and Literature Review, 6(2), 109-116.

[2] Allen, E., \& Seaman, J. (2013). Changing course: Ten years of tracking online education in the United States. Journal of Computing in Higher Education, 19(2), 98-120.

[3] Allias, A.A., Manan, N.A., Yusof, J., \& Pandian, A. (2012). Language learning strategy training using an online tool. International Journal of Social Science \& Education, 2(4), 587-597.

[4] Alon, T., Doepke, M., Olmstead-Rumsey, J., \& Tetilt, M. (2020). The impact of COVID-19 on gender equality. International Journal of Current Research, 47(3), 68-87.

[5] Alpala, C., \& Florez E.E. (2011). Blended learning in the teaching of english as foreign language: An educational challenge. Journal of Education and Human Development, 18(4), 154-168.

[6] Anderson, T., Rourke, L., Garrison, D.R., \& Archer, W. (2001). Assesing teaching presence in a computer conferencing context. Journal of Asynchronous Learning Networks, 5(2), 1-17.

[7] Andreatos, A. S. (2012). Educating the 21st century's engineers and IT professionals new media communication skills for engineers and IT professionals: Trans-national trans-cultural demands. Educational Technology \& Society, 132-159.

[8] Atmojo, A.E.F., \& Nugroho, A. (2020). EFL lasses must go online! Teaching activities and challenges during COVID-19 pandemic in Indonesia. Register Journal, 13(1), 49-76.

[9] Baber, H. (2020). Determinants of students' perceived learning outcome and satisfaction in online learning during the pandemic of COVID 19. Journal of Education and e-learning Research, 7(3), 285-292.

[10] Bae, J., \& Kim, G. (2018). A study into students' use of digital learning strategies in tertiary education. Teaching English with Technology, 20(1), 21-42.

[11] Bae, J., \& Kim, G. (2018). A study on Korean high school students' use of digital English learning environments focusing on the interrelations between learning strategies and learner variables. Secondary English Education, 11(1), 19-43. 
[12] Bayad, R., \& Bayad, C. M. (2020). Laying the groundworks for education of children in the new normal: The case of DepEd in Southern Mindanao. Eubios Journal of Asian and International Bioethics, 30(8), 443-449.

[13] Braun, V., \& Clarke, V. (2006). Using thematic analysis in psychology. Qualitative research in Psychology, 3(2), 77-101.

[14] Bhaumik, R., \& Priyadarshini, A. (2020). E-readiness of senior secondary school learners to online learning transition amid COVID-19 lockdown. Asian Journal of Distance Education, 15(1), 244-256.

[15] Bezhovski, Z., \& Poorani, S. (2016). The evolution of e-learning and new trends. Information and knowledge management, 6(3), 50-56.

[16] Blackmon, S., \& Major, C. (2012). Students' experiences in online courses: A qualitative research synthesis. The Quarterly Review of Distance Education, 13(2), 77-85.

[17] Blignaut, A.S., \& Trollip, S.R. (2003). Measuring faculty participation in asynchronous discussion forums. Journal of Education for Business, 78(6), 347-352.

[18] Booth, S., \& Marton, K. (1997). Learning and awareness. Journal of Teacher Education, 37(3), 43-50.

[19] Braun, V., \& Clarke, V. (2006). Using thematic analysis in psychology. Qualitative Research in Psychology, 3(12), 77-101.

[20] Brown, D., \& Lee, H. (2015). Teaching by principles: An interactive approach to language pedagogy. British Journal of Educational Technology, 39(5), 775-789.

[21] Buckler, A., Chamberlain, L., \& Stutchbury, K. (2020). Minimizing distance in distance learning programmes during a global health crisis: framing an international education response to COVID-19. Journal of Public Administration Research and Theory, 67(3), 56-67.

[22] Chen, C., Kao, H., \& Wu, W. (2012). Review of trends from mobile learning studies: A meta-analysis. Journal of Instruction Delivery Systems, 59(4), 817-827.

[23] Chen, P.D., Lambert, A.D., \& Guidry, K.R. (2010). Engaging online learners: The impact of web-based learning technology on student engagement. Journal of College Student Development, 5(4), 1222-1232.

[24] Cohen, V. L. (2003). Distance learning instruction: A new model of assessment. Journal of Computing in Higher Education, 14(2), 98-120.

[25] Dennen, V. P. (2005). From message posting to learning dialogues: Factors affecting learner participation in asynchronous discussion. Distance Education, 26(1), 127-148.

[26] Dillenbourg, P., \&. Schneider, D. (2002). Virtual learning environments. Learning and Instruction in Multiple Contexts and Settings, 65-71.

[27] Dominguez, P., \& Ridley, D.R. (2001). Assessing distance education courses and discipline differences ineffectiveness. Journal of Instructional Psychology, 28(1), 15-19.

[28] Dong, C., Cao, H., \& Lee, H. (2020). Young children's online learning during COVID-19 pandemic: Chinese. Children and Youth Services Review.

[29] Dumbford, A.D., \& Miller, A.L. (2018). Online learning in higher education: exploring advantages and disadvantages for engagement. International Journal of Instructional Technology \& Distance Learning, 31(2), 23-55.

[30] Evans, C. (2014). Twitter for teaching: can social media be used to enhance the process of learning? British Journal of Education Technology, 45(5), 902-915.

[31] Forbes. (2020). Why online learning is failing our nations' most vulnerable students. Digital smarts: Enhancing learning \& teaching, 82-103.

[32] Forbes, D. \&. (2019). From confounded to common ground: Misunderstandings between tertiary teachers and students in online discussions. Australasian Journal of Educational Technology, 35(4), 2-13.

[33] Forbes, D. L., \& Gedera, D. (2013). Footprints: participant perspectives informing pedagogy for asynchronous online discussion in initial teacher education. Journal of Research on Technology in Education, 36(2), 137-142.

[34] Garrison, D. (2011). E-learning in the 21st century: A framework for research and practice. American Journal of Distance Education, 15(1), 723.

[35] Gedera, D. S. P., Williams, J., \& Wright, N. (2015). Identifying factors influencing students' motivation and engagement in online courses Journal of Research on Technology in Education, 39(6), 13-23.

[36] Georgiou, S. N. (2002). Parental attributions as predictors of involvement and influences on child achievement. British Journal of Educational Psychology, 53(2), 304-325.

[37] Giannini, S., \& Albrecsten, A. (2020). COVID-19 school closures around the world will hit girls the hardest. International Association of Universities, 6(17), 58-63.

[38] Halupa, C. (2008). Risks: The impact of online learning and technology on student physical, mental, emotional, and social health. Journal of School Health, 78(3), 165-171.

[39] Han, I., \& Shin, W.S. (2016). The use of a mobile learning management system and academic achievement of online students. Computers and Education, 43(1), 79-89.

[40] Harding, J. (2018). Qualitative data analysis: From start to finish. SAGE Publications Limited.

[41] Islam, N., Beer, M. \& Slack, F. (2015). E-learning challenges faced by academics in higher education: A literature review. Journal of Education and Training Studies, 3(5), 102-112.

[42] Jamshed, S. (2014). Qualitative research method-interviewing and observation. Journal of Basic and Clinical Pharmacy, 5(4), 87-88.

[43] Jan, H. (2017). Teacher of 21st-century characteristics and development. Research on Humanities and Social Sciences, 7(9), 50-54.

[44] Jan, A. (2020). A phenomenological study of synchronous teaching during covid-19: A case of an international school in Malaysia. Social Sciences \& Humanities, 2(16), 1-10

[45] Lai, C., \& Kristonis, W. (2006). The advantages and disadvantages of computer technology in second language acquisition. Doctoral Forum National Journal for Publishing and Mentoring Student Research, 3(1), 1-5.

[46] Li, J. (2005). An empirical study on learning strategies of tertiary EFL learners in China. The Journal of Asia TEFL, 2(1), $131-154$.

[47] Lowenthal, P., \& Dunlap, J.C. (2014). Problems measuring social presence in a community of inquiry. E-Learning and Digital Media, 11(1), 2031.

[48] Lynch, M. M. (2004). Learning online: A guide to success in the virtual classroom. Journal of Teacher Education, 4(8), 43-50.

[49] Maguire, M., \& Delahunt, B. (2017). Doing a thematic analysis: A practical, step-by-step guide for learning and teaching scholars. All Irelend Journal of Teaching and Learning in Higher Education, 8(3), 3351-3364. 
[50] Mahyoob, M. (2020). Challenges of e-learning during the covid-19 pandemic experienced by EFL learners. Arab World English Journal, 11(4), 351-362.

[51] Mohalik, R., \& Sahoo, S. (2020). E-readiness and perceptions of student teachers' towards online learning in the midst of COVID-19 pandemic. SSRN Electronic Journal, 52(6), 11-19.

[52] Murphy, R. (2014). Learning online: What research tells us about whether, when, and how. Journal of community psychology, 43(5), 34-46.

[53] Nguyen, T. (2015). The effectiveness of online learning: beyond no significant difference and future horizons. MERLOT Journal Online Learning and Teaching, 11(2), 309-318.

[54] Ortiz, Y. (2017). The Impact of Learning Environments on Student Engagement. Education Statistics Quarterly, 26(3), 42-43.

[55] Owusu, L.D., \& Manso, K.F. (2020). The impact of COVID-19 on children from poor families in Ghana and the role of welfare institutions. Journal of Children Services, 15(4), 12-15.

[56] Oxford, R. L. (1990). Language learning strategies: What every teacher should know. Language Learning, 50(2), 203-244.

[57] Pandit, S. (2020). Sankatma nirantar sikai gorkhaparta. The Kantipur News, 32(6), 34-50.

[58] Phuyal, D. (2020). Challenges of virtual classes. The Himalayan, 14(3), 34-45.

[59] Pollack, P. H., \& Wilson, B. M. (2002). Evaluating the impact of internet teaching: Preliminary evidence from American national government classes. PS. Political Science and Politics, 35(3), 561-566.

[60] Prensky, M. (2001). Digital native, digital immigrants on the horizon. International Journal of Educational Technology in Higher Education, $17(14), 88-111$.

[61] Pukkaew, C. (2013). Assessment of the effectiveness of internet-based distance learning through the VClass e-Education platform. International Review of Research in Open and Distance Learning, 14(4), 255-276.

[62] Ramos, S., Francisco, W., Leduna, N., Librado, K.S., Pabraquel, M.K., Deran, J., \& Alieto, E. (2020). Substituting English with a local language: Examining parents belief toward Chavacano as a language of instruction. Asian EFL Journal research Articles, 21(1), $177-194$.

[63] Richards, J. C., Platt, J., Platt, H. (1992). Longman dictionary of language teaching and applied linguistics. Teaching English with Technology, 13(7), 65-71.

[64] Richardson, J. T. E., Morgan, A., \& Woodley, A. (1999). Approaches to studying distance education. Review of Higher Education, $37(6), 23-55$.

[65] Ryan, G., \& Woodley, H. (2000). Data management and analysis methods. Handbook In Qualitative Research, 2(15), 769-802.

[66] Saraswati, D. (2020). Impact of COVID-19 on the education sector in Nepal: challenges and coping. The Turkish Online Journal of Educational Technology, 5(4), 1-5.

[67] Schlechty, P. (2002). Working on the work: An action plan for teachers, principals, and superintendents. Journal of Interior Design, 27(1), 3444.

[68] Schrander, D. E. (2015). Constructivism and learning in the age of social media: Changing minds and learning communities. New Directions for Teaching and Learning, 14(4), 23-35.

[69] Sharma, L. (2020). Think Local: Support for learning during COVID-19 could be found from within communities. British Journal of Educational Psychology, 69(3), 409-432.

[70] Singh, V., \& Thurman, A. (2019). How many ways can we define online learning? A systematic literature review of definitions. American Journal of Distance Education, 33(4), 289-306.

[71] Smart, K. L., \& Cappel, J. J. (2006). Students' perceptions of online learning: A comparative study. Journal of Information Technology Education, 5(1), 4-7.

[72] Smith, L., \& Northcote, M. (2016). Community in Online Higher Education: Challenges and Opportunities. European Journal of Open, Distance and E-learning, 39(1), 99-111.

[73] Sobel, D., \& Sands, D. (2007). Supporting students' cognitive processing in online courses: Designing for deep and meaningful student-tostudent-content situations. TechTrends, 51(4), 20-31.

[74] Stallings, D. (2002). Measuring success in the virtual university. The Journal of Academic Librarianship, 28(4), 47-53.

[75] Teo, T. (2013). Initial development and validation of a Digital Natives Assessment Scale (DNAS). Computer and Education, 67(4), 51-57.

[76] Tess, P. A. (2013). the role of social media in higher education classes real and virtual: A literature review. Computers in human behavior, 29(3), 60-68.

[77] Tiruneh, D. (2020). COVID-19 school closures may further widen the inequality gaps between the advantaged and the disadvantaged in Ethiopia. Journal of Labor Economics, 54(12), 345-360.

[78] Tomei, L. A. (2006). The impact of online teaching on faculty load: Computing the ideal class size for online courses. Journal of Technology and Teacher Education, 14(2), 531-541.

[79] Tria, J. (2020). The covid-19 pandemic through the lens of education in the Philippines: The New Normal. International Journal on Pedagogical Development and Lifelong Learning, 1(1), 1-4.

[80] Vox, R. L. (2020). The shift to online learning could worsen educational inequality. Information Systems Frontiers, 5(2), $207-216$.

[81] Wenden, A., \& Rubin, J. (2011). Learner strategies in language learning. International Journal of Educational Technology in Higher Education, 14(38), 1-18.

[82] Yang, Y. \&. (2004). Students perception towards the quality of online education: A qualitative approach. Association for Educational Communications and Technology, 861-876.

[83] Yun, I. (2013). E-language learning platform: problems and challenges. 60th TEFLIN International Conference, 65(4), 27-29. 